Esta revista forma parte del acervo de la Biblioteca Jurídica Virtual del Instituto de Investigaciones Jurídicas de la UNAM

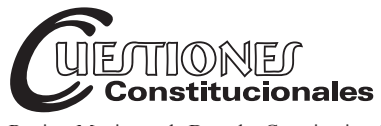

Revista Mexicana de Derecho Constitucional

Núm. 44, Enero-Junio 2021

ISSN (versión electrónica): 2448-4881

\title{
La jurisdicción constitucional y la institucionalidad democrática en Venezuela: Balance y desafíos
}

\section{Constitutional jurisdiction and democratic institutionality in Venezuela: Balance and challenges}

Recepción: 28 de agosto del 2019

Aceptación: 15 de junio del 2020

\author{
Jesús María CASAL*
}

RESUMEN: Este artículo analiza el papel que ha desempeñado la Sala Constitucional del Tribunal Supremo de Justicia de Venezuela en el desmantelamiento de la institucionalidad democrática que se ha producido en ese país. Se identifican las bases conceptuales y procesales en que se ha apoyado dicha Sala para apuntalar una dominación autoritaria. El autor aborda la importante misión cumplida por tribunales constitucionales en procesos de transición a la democracia o de redemocratización y, a partir de allí, plantea los principales desafíos que debería asumir una jurisdicción constitucional renovada en su integración y en su concepción funcional con la finalidad de asegurar el pluralismo político y el Estado de Derecho en Venezuela. Se señalan también las prácticas procesales y las interpretaciones que deberían ser abandonadas y las que habría que promover.
ABSTRACT: This article analyses the role played by the Constitutional Chamber of the Supreme Court of Justice of Venezuela in the dismantling of democratic institutions that has occurred in that country. The conceptual and procedural foundations on which the Constitutional Chamber relied on to endorse an authoritarian domination are identified. The author refers to the important mission accomplished by the constitutional courts in processes of transition to democracy or redemocratization and highlights the main challenges that a constitutional jurisdiction, with a new integration and functional conception, should address to ensure political pluralism and the rule of law in Venezuela. The study also comprises the procedural practices and the interpretations that should be abandoned and those that should be promoted.

* Profesor de Derecho Constitucional en la Universidad Católica Andrés Bello (Caracas). Senior Research Affiliate en el Instituto Max Planck de Derecho Público Comparado y Derecho Internacional (Heidelberg). Venezuela. Correo electrónico: jesusmariacasal@gmail.com. ORCID: 0000-0001-9684-3691. 
Esta revista forma parte del acervo de la Biblioteca Jurídica Virtual del Instituto de Investigaciones Jurídicas de la UNAM

Finalmente, el autor enuncia algunas herramientas que podrían robustecer la autoridad de tal jurisdicción en una posible transición a la democracia.

Palabras clave: papel de la jurisdicción constitucional, autoritarismo judicial en Venezuela, tribunales constitucionales y transición a la democracia, desafíos procesales y sustantivos.
Finally, the article presents some tools that could strengthen the authority of such jurisdiction in a possible transition to democracy.

Keywords: Role of the Constitutional Jurisdiction, Judicial Authoritarianism in Venezuela, Constitutional Courts and Transition to Democracy, Procedural and Substantive Challenges.

\begin{abstract}
SUMARIO: I. Introducción. II. La jurisdicción constitucional y la transición a la democracia. III. El papel político-institucional de la Sala Constitucional del Tribunal Supremo de Justicia. IV. Los elementos conceptuales y las estrategias procesales puestos al servicio del autoritarismo ejecutivo y judicial. V. La jurisdicción constitucional de la redemocratización.

VI. Conclusión. VII. Fuentes consultadas.
\end{abstract}

\title{
I. INTRODUCCIÓN
}

Venezuela ha sufrido un proceso severo de demolición de la democracia y el Estado de derecho que ha dado lugar a múltiples informes de organismos internacionales, como la Oficina del Alto Comisionado de las Naciones Unidas para los Derechos Humanos (2019) y a numerosos estudios científicos, algunos centrados en sus contenidos e implicaciones políticoconstitucionales (González-Jácome, 2019, pp. 136 y ss. y Landau, 2013, pp. 189 y ss.). En este trabajo se quiere focalizar el análisis en la actuación desplegada por la Sala Constitucional (SC) del Tribunal Supremo de Justicia, en ese contexto de degradación institucional que ella misma ha sabido impulsar, y en los cambios sustanciales que, desde una jurisdicción constitucional comprometida con la hoy incipiente transición a la democracia, habría que adoptar para renovar dicha jurisdicción en sentido conceptual y funcional y perfilarla como un agente fundamental de la redemocratización.

Es importante considerar el papel que debería jugar la jurisdicción constitucional en el escenario de recuperación democrática que podría iniciarse en Venezuela (Asamblea General de la Organización de Estados Americanos, 2019). En este país, las fuerzas democráticas representadas 
Esta revista forma parte del acervo de la Biblioteca Jurídica Virtual del Instituto de Investigaciones Jurídicas de la UNAM

en la Asamblea Nacional se esfuerzan por lograr el establecimiento de un verdadero orden constitucional y democrático, lo cual implica la convocatoria de elecciones genuinas y una regeneración institucional basada en el Estado de Derecho. La experiencia comparada indica que, en la transición a la democracia, los tribunales constitucionales suelen contribuir significativamente al desmontaje de las estructuras y de los criterios autoritarios que de una forma $\mathrm{u}$ otra intentan persistir a pesar de la transformación política. De allí que, ante ese escenario, sea preciso reflexionar sobre el perfil y retos de la jurisdicción constitucional, lo cual presupone comprender los cimientos del protagonismo de la Sala Constitucional del Tribunal Supremo de Justicia en el desmantelamiento de la democracia y el Estado de Derecho e identificar las desviaciones jurisprudenciales que deben ser superadas.

Seguidamente se hará referencia al desempeño de la jurisdicción constitucional en algunos procesos de transición a la democracia, en los cuales los aportes de los tribunales constitucionales han sido justamente valorados como trascendentales y han servido de modelos en circunstancias institucionales similares. Luego se aludirá al rol que hasta la fecha ha cumplido la Sala Constitucional del Tribunal Supremo de Justicia y se examinarán los elementos conceptuales y procesales que han caracterizado su andadura autoritaria. Finalmente, se abordarán algunas de las tareas que debería asumir la jurisdicción constitucional venezolana en una transición a la democracia y algunos de los mecanismos que podrían coadyuvar al afianzamiento de su autoridad en esa fase decisiva.

Conviene aclarar que cuando se menciona la jurisdicción constitucional se deja abierta la cuestión de la denominación y organización de la instancia que ocuparía una posición especial dentro del sistema de justicia constitucional, al ostentar competencias de control concentrado (eventualmente anulatorio) de la constitucionalidad de las leyes, entre otras. El concepto de jurisdicción constitucional es frecuentemente referido a la facultad de control judicial de constitucionalidad de las leyes con efectos anulatorios o tendencialmente generales, reservada a determinado órgano jurisdiccional (Rubio Llorente, 2012, pp. 1251 y 1252, 1325 y 1326).

En este trabajo se parte de la premisa de que se mantendrá en el país una jurisdicción constitucional en sentido amplio, bajo uno u otro diseño institucional (corte suprema de justicia con atribuciones de control concentrado, sala o tribunal constitucional), aunque dentro de un sistema mixto o integral de justicia constitucional, que se corresponde con nuestra evolución 
Esta revista forma parte del acervo de la Biblioteca Jurídica Virtual del Instituto de Investigaciones Jurídicas de la UNAM

constitucional y que apunta en la dirección de una defensa judicial de la Constitución colocada en manos de actores plurales, de jueces autónomos que a la luz de los casos concretos van impulsando la construcción de la jurisprudencia constitucional y desaplican leyes u otras normas incompatibles con la Constitución (control difuso), con atribuciones de control concentrado (anulatorio) de constitucionalidad de las leyes y de armonización jurisprudencial, entre otras, a cargo del órgano de jurisdicción constitucional. Esta preservación del modelo mixto, además, evita sobredimensionar la posición del órgano encargado de la jurisdicción constitucional, con los riesgos que ello puede comportar para la democracia y el Estado de Derecho. La existencia de un órgano que tenga esas competencias anulatorias y de armonización es, al mismo tiempo, importante para la protección de la Constitución, el resguardo de la democracia y el mejor funcionamiento del sistema de justicia constitucional como un todo. Por otra parte, no debe descartarse que, según las características de la transición política, la figura de la Sala Constitucional integrada en un Tribunal Supremo de Justicia deba conservarse, así fuera como solución provisoria, aunque evidentemente renovada en su composición.

\section{LA JURISDICCIÓN CONSTITUCIONAL Y LA TRANSICIÓN}

A LA DEMOCRACIA

En los últimos años ha cobrado singular interés el estudio de la misión o papel institucional de los tribunales constitucionales o de la jurisdicción constitucional (Boulanger, 2013 y Casal, 2010a). Ello en dos vertientes fundamentales. Por un lado, la de los análisis actitudinales y otros aportes de la doctrina norteamericana centrados en los factores que explican el comportamiento y decisiones judiciales, en especial de los jueces de la Suprema Corte de los Estados Unidos y, por otro lado, la de las investigaciones principalmente europeas relativas al papel de los tribunales constitucionales en procesos de transición a la democracia, como los vividos en Europa del Este. Los primeros han mostrado que un aspecto crucial en la comprensión de la actuación de los jueces constitucionales es la conciencia que tienen sobre la misión que han de cumplir y se espera de ellos. Las segundas ponen de manifiesto que, justamente, desde la perspectiva de su conciencia institucional, los tribunales constitucionales han procurado 
Esta revista forma parte del acervo de la Biblioteca Jurídica Virtual del Instituto de Investigaciones Jurídicas de la UNAM

desempeñar un rol relevante en tales procesos de transformación y a veces lo han logrado.

Este auge de la aproximación funcional a la jurisdicción constitucional se ha visto reflejado también en la profundización en el examen de la actividad jurisdiccional de los tribunales constitucionales en Italia, Alemania y España, durante la recuperación democrática experimentada tras la Segunda Guerra Mundial, en los dos primeros casos, o después de la caída del franquismo, en el último.

En el ámbito latinoamericano el interés por estos enfoques ha aumentado a raíz de la tragedia institucional venezolana, con la Sala Constitucional del Tribunal Supremo de Justicia como artífice fundamental de la demolición de la democracia y el Estado de Derecho. Es preciso robustecer en la región el tratamiento científico de las funciones institucionales de la jurisdicción constitucional, según lo expuesto en trabajos previos de perspectiva comparada o referidos a la situación constitucional venezolana (Bazán y Nash, 2011, y Casal, 2010a). Hay que propugnar una comprensión de la jurisdicción constitucional que la perfile cada vez con más vigor como una jurisdicción constitucional de la libertad, como un conjunto orgánico y procesal destinado a resguardar la separación de poderes, el pluralismo político y social, la autonomía individual y los derechos fundamentales en general. Es importante además revisar esta concepción funcional de la jurisdicción constitucional en distintos ordenamientos jurídicos (Nogueira Alcalá, 2004, pp. XVI y ss.; Rubio Llorente, 2012, pp. 1373 y ss.; Tajadura, 2006, pp. 521 y ss.; Brewer-Carías, 2010, 25 y ss.; Colombo, 2002, 11 y ss.; Corzo, 2013, pp. 133 y ss.; Paredes, 2015, pp. 245 y ss.). De este modo, se sale al paso de corrientes que pudieran preconizar una jurisdicción constitucional pretendidamente neutral, sin identidad funcional específica, o de aquellas puestas al servicio de una ideología metaconstitucional o de una dominación personal o autoritaria. En otras palabras, ello puede coadyuvar a contrarrestar ciertas tendencias de "constitucionalismo abusivo" (Landau, 2013, pp. 189 y ss.) que han sido observadas en Venezuela y otros países.

En particular, la discusión sobre los aspectos organizativos y funcionales de la jurisdicción constitucional, sin duda importante, no debe dejar de lado la cuestión medular: la razón de ser o la misión institucional de esa jurisdicción. No es suficiente decir que su tarea consiste en asegurar el cumplimiento de la Constitución, quedando así el papel de los tribunales o salas constitucionales diluido en el complejo entramado de la regulación 
Esta revista forma parte del acervo de la Biblioteca Jurídica Virtual del Instituto de Investigaciones Jurídicas de la UNAM

constitucional, sino que la formación y evolución de esta jurisdicción en el constitucionalismo comparado la ha ido dotando de un perfil funcional específico, que obviamente no está divorciado de la normativa constitucional pero que no se agota en su literalidad.

El repunte o marcha triunfal de los tribunales constitucionales europeos se origina en la segunda posguerra, como reacción ante la incapacidad de los ordenamientos constitucionales de defenderse frente al avance autoritario o totalitario del fascismo o el nacionalsocialismo (Fernández Segado, 1997, pp. 45 y ss.). Un aspecto capital de esta génesis se encuentra en la observación de los procesos de perversión de la institucionalidad, de socavamiento interno, que habían tenido lugar especialmente en Alemania, frente a los cuales el tribunal constitucional era concebido como máximo garante de los pilares fundamentales de un orden democrático-constitucional y, por tanto, de los derechos inherentes al ser humano. Dichos tribunales (re) surgieron, pues, no como una pieza más de la ingeniería constitucional, sino con la misión específica de evitar la concentración y absolutización del poder del Estado y de mantener saludables los resortes o contrapesos orgánico-funcionales. Igualmente, para amparar los espacios públicos de debate y competencia democráticos y los de libertad individual y social.

Tras los intentos fallidos de entreguerras, este bautizo o regeneración de la jurisdicción constitucional, como instrumento esencial de la preservación de los equilibrios políticos, de los pesos y contrapesos del Estado de Derecho dentro de la democracia, como garantía del respeto de la dignidad del ser humano y de los derechos que le son inherentes, ha dejado una impronta imborrable en la concepción del rol institucional que debe desempeñar. Algo similar puede decirse de los desarrollos jurisprudenciales estadounidenses ligados a la protección de la declaración de derechos. Estos progresos impactaron en Latinoamérica, que recorría su propio camino de constitucionalización, y que en general hizo pivotar su justicia constitucional en la garantía efectiva de los derechos humanos, con el amparo como mecanismo procesal representativo de este movimiento en favor de la protección procesal de los derechos.

El asentamiento de esa idea sobre las funciones de la jurisdicción constitucional explica que, cuando los países de Europa del Este acometieron sus procesos de transición a la democracia, incorporaran en sus Constituciones tribunales constitucionales, como signos inequívocos del compromiso con la democracia constitucional que estaban asumiendo. Algunos 
Esta revista forma parte del acervo de la Biblioteca Jurídica Virtual del Instituto de Investigaciones Jurídicas de la UNAM

de estos tribunales jugaron después un rol relevante en la democratización de tales Estados.

Hoy los tribunales o salas constitucionales, u órganos judiciales supremos encargados de la jurisdicción constitucional, conceptualmente no son simples defensores de la Constitución, sino que lo son con un determinado sello funcional-institucional. Son creados sobre todo para salvaguardar la idea misma de Constitución como instrumento de limitación y control del poder. También, por tanto, para actuar como instancia judicial última de garantía de los derechos humanos o derechos fundamentales en el orden interno. No tanto porque tales órganos, de manera global, puedan asegurar en solitario su observancia, sino porque están particularmente llamados a preservar, por las formas y medios de la jurisdicción, el ecosistema democrático constitucional en que operan y en que esos derechos han de ser normalmente respetados.

El afianzamiento de una visión institucional como la esbozada erige a la jurisdicción constitucional en guardián no solo de la Constitución o de la supremacía constitucional a secas, sino especialmente del sistema democrático-constitucional, cuya vigencia es necesaria para que queden resguardados los derechos y libertades y la participación libre de la ciudadanía en los asuntos públicos, lo cual conduce a que el entendimiento que tienen los jueces constitucionales sobre su propio cometido atienda a tales paradigmas, más aún si estos se han sembrado en la comunidad jurídica y en la sociedad en su conjunto, ante la cual aquellos habrán de rendir cuentas de sus ejecutorias. Se trata no de encomendar a la jurisdicción constitucional la misión hercúlea, y peligrosa a la luz del Estado de Derecho, de asegurar que la democracia constitucional se conserve saludable, como base o fundamento para una intervención judicial cada vez que, con ese propósito, los jueces constitucionales lo consideren necesario, sino de continuar ejerciendo las facultades propias de esa jurisdicción, de revisión de la constitucionalidad de las leyes u otras de garantía judicial de la Constitución, en el marco de las competencias y procesos correspondientes, pero intensificando el control cuando puedan haber sido puestos en entredicho los cimientos o fundamentos del edificio constitucional-democrático, en una dimensión tanto sustantiva como procedimental.

Por otro lado, aunque no baste para contrarrestarlas, esa perspectiva funcional puede ser un antídoto o contención ante las amenazas autoritarias de uno u otro signo ideológico que están al acecho de nuestras frágiles democracias y de nuestros incipientes Estados de Derecho. La premisa 
Esta revista forma parte del acervo de la Biblioteca Jurídica Virtual del Instituto de Investigaciones Jurídicas de la UNAM

esencial de todo esto es, por supuesto, la independencia judicial, pues una vez que esta ha sido enteramente socavada los factores que influyen en el comportamiento judicial son de otra naturaleza. Respecto de este socavamiento de la independencia judicial en Venezuela, conviene ver lo que distintos autores como Canova, Herrera, Rodríguez y Graterol (2014), Chavero (2011) y Louza (2017) han señalado en sus estudios sobre el tema.

En contextos de transición a la democracia o redemocratización, la jurisdicción constitucional ha llegado a ser actor fundamental de la reinstitucionalización, como, entre otros autores, ha señalado Ahumada (2005), dado que desde ese órgano instaurado en el vértice jurisdiccional ha sido posible impregnar todo el poder judicial y el sistema jurídico del espíritu que anima la reconstrucción. Ha sido arquetípica la experiencia alemana de la segunda posguerra y, después, la española del posfranquismo. Los respectivos tribunales constitucionales asumieron posiciones de vanguardia en la defensa del corazón de las nuevas Constituciones, de sus principios rectores y de los derechos consagrados. Supieron levantar la naciente idea constitucional, por medio de una temprana jurisprudencia que se empeñó en dar señales claras de la instauración de un orden jurídico-político sustancialmente distinto del anterior.

La jurisprudencia del Tribunal Constitucional Federal Alemán, referida a los derechos fundamentales como orden o sistema de valores, con las depuraciones a que luego sería sometida, fue expresión de la especial significación que tendrían estos derechos y su garantía judicial efectiva en la fase de recuperación republicana y democrática que se iniciaba, como ha sido reseñado por Boulanger (2013, pp. 73 y ss.). Al mismo tiempo, quería poner de manifiesto la ruptura con las situaciones precedentes de negación abierta de estos derechos y de la dignidad de la persona durante el Nacionalsocialismo, así como con la limitada protección judicial de estos derechos y las fragilidades de la dogmática jurídica en la República de Weimar.

El Tribunal Constitucional español por su parte, con sentencias como las referidas al derecho de reunión o manifestación, sin necesidad de autorización previa, o a la objeción de conciencia, como derecho cuya operatividad no podía quedar completamente suspendida hasta la adopción de la ley correspondiente (SSTC 15/1982 y 36/1982), apuntaló líneas jurisprudenciales en materia de derechos que reivindicaron la fuerza normativa de la Constitución y que obligaron a una relectura del ordenamiento jurídico bajo la égida de la Constitución (Garzón Valdés, 2003, 27 y ss.). 
Esta revista forma parte del acervo de la Biblioteca Jurídica Virtual del Instituto de Investigaciones Jurídicas de la UNAM

Tanto en el caso alemán como en el español, los tribunales constitucionales representaban piezas nuevas dentro de una institucionalidad que en parte conservó cuadros del régimen precedente. En Alemania, fue eliminado el Tribunal Superior Popular, pero muchos de los jueces de tribunales ordinarios se mantuvieron en sus posiciones en la posguerra. Incluso jueces del Tribunal Supremo Federal procedían del poder judicial anterior a la caída del Nacionalsocialismo. Mientras que en el Tribunal Constitucional Federal fueron designados exiliados o personas con una orientación claramente diferente a la del sistema que había colapsado (Boulanger, 2013, 73 y ss.). En España, por las características de la transición ordenada y gradual desde el franquismo y hacia la democracia, el poder judicial siguió siendo en importante medida el mismo. Hubo cambios relevantes como la supresión del Tribunal de Orden Público, pero el resto de la estructura judicial en términos generales soportó la transición y en ella prevalecía una mentalidad que privilegiaba el valor del orden, de la estabilidad social y del respeto a la autoridad. Sobre ella se superpuso un Tribunal Constitucional con orientaciones vanguardistas en la garantía de las libertades fundamentales (Rubio Llorente, 2012, 1409 y ss. y García de Enterría, 1981, pp. 19 y ss.), lo cual venía exigido por la Constitución y por los pasos dados antes de su aprobación, y se reflejaba también en su composición.

En ambos contextos los tribunales constitucionales empujaron a los demás órganos judiciales en la dirección de la protección del Estado de Derecho, con los derechos fundamentales como acicate principal de este giro jurisprudencial. El ordenamiento jurídico en su conjunto adquirió un sentido distinto, gracias en parte a esta tarea, con lo cual los engranajes del pasado se transformaron e insertaron en una dinámica democrática y constitucional muy diversa.

Bajo estas coordenadas, conviene abordar el papel institucional que ha jugado la Sala Constitucional del Tribunal Supremo de Justicia y el que debería cumplir la futura jurisdicción constitucional.

\section{EL PAPEL POLÍTICO-INSTITUCIONAL DE LA SALA

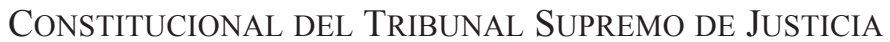

De acuerdo con la Constitución, la Sala Constitucional, como parte del Tribunal Supremo de Justicia, debería ser un órgano que contribuyera a garantizar la supremacía y efectividad de las normas y principios constitu- 
Esta revista forma parte del acervo de la Biblioteca Jurídica Virtual del Instituto de Investigaciones Jurídicas de la UNAM

cionales (artículo 335). Esta contribución tendría que ser además decisiva, dada la singular función que está llamada a cumplir en la interpretación de la Constitución, en virtud del efecto vinculante de los criterios que al respecto establece. Por otro lado, aunque la Constitución no lo señale expresamente, de ésta y de lo antes expuesto se desprende que dicha Sala debería ser un actor institucional fundamental para asegurar la vigencia del Estado de derecho y de los principios democráticos. De allí la importancia que habrían de tener en su actuación la protección de los derechos humanos y la preservación de la separación o división de poderes y del pluralismo político (artículos 2o., 3o., 19, 23 y 136 de la Constitución).

Sin embargo, la Sala Constitucional, creada por la Constitución de 1999, se desvió rápidamente del modelo constitucional y del paradigma filosófico-jurídico del constitucionalismo. Había sido instaurada bajo el impulso de propuestas que respondían mayoritariamente a la idea de robustecer la salvaguarda de los derechos humanos y de la Constitución como expresión del constitucionalismo democrático, pero quedó atrapada tempranamente por la determinación de las fuerzas partidistas dominantes de ocupar políticamente el Tribunal Supremo de Justicia. El propio sobredimensionamiento funcional de la Sala Constitucional que se puso de manifiesto en la supuesta Exposición de Motivos de la Constitución (Casal, 2000), redactada con posterioridad a la sanción popular de la Constitución y en muchos aspectos alejada del texto y de la voluntad constituyente, anunciaba ya el propósito de los dueños del proceso político emergente de erigir a dicha Sala en un instrumento de cierre de todo el orden jurisdiccional y, en tal condición, en la garantía última de los fines e intereses gubernamentales.

La propia Sala se inclinó desde el comienzo por una lectura extensiva de sus atribuciones, invocando de manera postiza la misión de coadyuvar al aseguramiento de la supremacía constitucional. La Sala no sólo ignoró esta tarea, que en igual sentido tienen asignadas otras Salas del Tribunal Supremo de Justicia, en su ámbito competencial, sino que, adicionalmente, asumió como objetivo la ampliación de su campo de actuación, antes que el cumplimiento de su papel institucional como jurisdicción constitucional de la libertad, como instancia jurisdiccional dedicada a desplegar controles sobre los gobernantes, a evitar el abuso de poder, para resguardar los derechos humanos y los equilibrios políticos.

Al inicio de su andadura jurisprudencial, dejó algunas muestras de protección constitucional, pero también desde entonces sembró los fundamentos para el progresivo y acelerado socavamiento de la instituciona- 
Esta revista forma parte del acervo de la Biblioteca Jurídica Virtual del Instituto de Investigaciones Jurídicas de la UNAM

lidad democrática, que llevaría a cabo con empeño y frente al cual de poco sirvieron en la práctica algunas señales tardías de parcial rectificación de alguno de los protagonistas de la embestida judicial. Tempranamente la labor de la Sala Constitucional arrojó un saldo francamente negativo en lo que respecta a los logros materiales que debe exhibir una jurisdicción constitucional que merezca tal nombre, como oportunamente fue advertido por Brewer-Carías (2007, pp. 11 y ss.) y Casal (2005, pp. 316 y ss.). Dicha Sala se perfiló crecientemente como un artífice primordial de la restricción arbitraria de las libertades civiles y políticas; de la extensión indebida de las facultades del Presidente de la República; de la minimización del valor de los tratados internacionales sobre derechos humanos; del desconocimiento de las posibilidades de acción de la oposición parlamentaria; del cercenamiento de la libertad económica y del derecho de propiedad y, aunque luzca paradójico, del debilitamiento de la garantía jurídica de los derechos sociales (Brewer Carías, 2007, pp. 470 y ss. y Casal, 2011, pp. 1811 y ss.).

La Sala Constitucional del Tribunal Supremo de Justicia ejemplifica de modo palmario las situaciones en las cuales la jurisdicción constitucional asume funciones de afianzamiento de una dominación autoritaria, tal como se refleja en distintos estudios (Brewer-Carías, 2016 y Casal, 2017a). Se trata de un órgano que no ejerce un auténtico control jurisdiccional; que resuelve sistemáticamente a favor del gobierno, con contadísimas excepciones correspondientes a sus primeros años de funcionamiento (Taylor; 2014, pp. 229 y ss.); que avala ampliamente las políticas o medidas oficiales y, lo que es más delicado, que frente a intereses o políticas gubernamentales contrarias a la libertad de expresión o de manifestación u otros derechos medulares para la democracia, se adelanta a la actuación pública y abre senderos para una intervención estatal más profunda, mayormente lesiva de esos derechos. Es un actor militante del menoscabo de las libertades ciudadanas, que actúa alineado con el gobierno nacional.

La Sala Constitucional ha sido, pues, un instrumento del régimen autoritario, aunque conviene aclarar que ha tenido cierta vida propia, en el sentido de que no ha sido un mero ejecutor de órdenes gubernamentales ni se ha limitado a convalidar las actuaciones oficiales al desechar de plano los recursos interpuestos contra ellas, sino que ha demostrado una especial capacidad de iniciativa, de invención y, en definitiva, de cooperación activa en la apertura de caminos de consolidación de la hegemonía de la ideología y del poder personal del Presidente. Esta vida propia no se basa obviamente en la independencia judicial, sino en la naturaleza del sistema 
Esta revista forma parte del acervo de la Biblioteca Jurídica Virtual del Instituto de Investigaciones Jurídicas de la UNAM

de dominación en el cual el poder judicial se inserta. El poder judicial, y sobre todo su cúspide, han adquirido en este ciclo una significación antidemocrática desconocida hasta ahora en Venezuela, según la cual el Tribunal Supremo de Justicia y particularmente su Sala Constitucional no son propiamente órganos de control jurisdiccional, ni siquiera de modo aparente o como fachada, sino que forman parte de las estructuras de apoyo militante a la ideología y a la gestión gubernamental. Habíamos tenido anteriormente serios problemas para afianzar un poder judicial autónomo, pero eran de otra naturaleza y alcance.

La Sala Constitucional no ha operado bajo las reglas de la iniciativa de parte interesada y de la presentación de los recursos correspondientes ni conforme a competencias específicas normativamente atribuidas, ni siquiera con apego al principio del contradictorio y al derecho a ser oído (Casal, 2017b, pp. 199 y ss., y SC 9/2016, 473/2016 y 2/2017). Su actividad se aproxima más a la de una instancia que, en consulta permanente con el gobierno, prepara estrategias simuladamente jurisdiccionales para ampliar las facultades ejecutivas, restar espacios de participación libre a la oposición o a la sociedad en general, catapultar las posibilidades de intervención del Estado en la economía y, correlativamente, relativizar el valor de los derechos económicos, así como de los derechos fundamentales en general. No ha sido en rigor un órgano jurisdiccional.

En tal sentido, la Sala Constitucional ha establecido interpretativamente los fundamentos para la reelección indefinida del Presidente de la República (SC 1488/2006); para la censura judicial de informaciones y de la programación de los medios de comunicación (SC 1013/2001 y 956/2007; Relatoría Especial para la Libertad de Expresión de la Comisión Interamericana de Derechos Humanos, 2003); para la ampliación del ámbito del reglamento en el campo de la actividad económica, en detrimento de la reserva de ley (SC 163/2004 y 2164/2004); para la utilización desmesurada de las leyes habilitantes y de los decretos leyes (SC 1716/2001 y 740/2003); para la denuncia de la Convención Americana sobre Derechos Humanos (SC 1939/2008); para la centralización de competencias constitucionalmente atribuidas a los Estados con el carácter de exclusivas (SC 565/2008); para la intervención estatal en la economía con mínimos límites sustantivos (SC 1049/2009 y 1158/2014), entre otros vectores jurisprudenciales favorecedores de la expansión del poder gubernamental (Brewer-Carías, 2007, pp. 419 y ss. y Casal, 2017a). 
Esta revista forma parte del acervo de la Biblioteca Jurídica Virtual del Instituto de Investigaciones Jurídicas de la UNAM

La labor judicial desarrollada por la Sala Constitucional una vez que la oposición al gobierno de Hugo Chávez y luego de Nicolás Maduro obtuvo un importante triunfo en las elecciones parlamentarias de 6 de diciembre de 2015 corrobora esa orientación general de la jurisprudencia constitucional y el papel institucional ya esbozado de la referida Sala. Antes de esos comicios, la Sala Constitucional se distinguió por respaldar la actuación del Poder Ejecutivo Nacional y de la Asamblea Nacional, mayoritariamente oficialista, al declarar sin lugar los recursos interpuestos contra sus actos. Más aún, su papel ha sido no solo de pasividad ante acciones inconstitucionales de los poderes públicos sino incluso se ha caracterizado, como se dijo, por anticiparse a las iniciativas gubernamentales, colocando argumentativamente bases para una "huida hacia adelante", es decir, para una intensificación o profundización de medidas ya adoptadas o de aspiraciones programáticas o intereses no satisfechos.

Esa misma Sala Constitucional, completamente postrada ante el ejecutivo o, mejor dicho, erigida en factor determinante de su dominación, sacó a relucir un rostro aún más autoritario cuando las circunstancias se lo exigieron. La oposición democrática ganó las dos terceras partes de los escaños de la Asamblea Nacional en las elecciones legislativas del 6 de diciembre de 2015, lo cual llevó a que la agónica mayoría oficialista de la Asamblea Nacional, cuyo periodo vencería en breve, anticipara inconstitucionalmente la designación de 13 magistrados principales y 20 suplentes del Tribunal Supremo de Justicia, mediante jubilaciones anticipadas frutos de la presión política, lo cual privaba a la nueva Asamblea Nacional de la posibilidad de renovar parcialmente este Tribunal en la oportunidad en que correspondía, diciembre de 2016.

Este Tribunal Supremo de Justicia y su Sala Constitucional, que pasaron a tener en diciembre de 2015 una composición todavía más abyecta, que no cabía imaginar, procedieron a acometer un plan sistemático de demolición del Parlamento, mediante la sustracción a la oposición de esa mayoría calificada, el bloqueo de las funciones de legislación y de control de la Asamblea Nacional y, finalmente, la completa anulación de este órgano parlamentario y de sus actos. Después de más de ochenta decisiones dictadas por la Sala Constitucional desde enero de 2016, sobre normas u otros actos o supuestas omisiones o sobre las facultades del Parlamento, todas desfavorables a la Asamblea Nacional y carentes de sustento y solidez constitucional, no queda espacio para la actuación con eficacia jurídica 
Esta revista forma parte del acervo de la Biblioteca Jurídica Virtual del Instituto de Investigaciones Jurídicas de la UNAM

de este órgano democrático-representativo, el cual es sin embargo la única expresión institucional genuina en Venezuela de legitimidad democrática.

La inmunidad parlamentaria ha sido pisoteada, en el marco de la persecución política, y la sociedad misma ha sido cercada por la represión y la violación de los derechos humanos, con una Sala Constitucional que sometió inconstitucionalmente el derecho de manifestación al requisito de la obtención de autorización previa (SC 276/2014); respaldó tácitamente el cierre arbitrario de la vía del referendo revocatorio como mecanismo de solución democrática de la crisis política y social (SC 2750/2003); eliminó el control parlamentario sobre la declaración ejecutiva de los estados de excepción y convalidó su prolongación indefinida (SC 7/2016); sentó los fundamentos para la cancelación de los partidos de oposición (SC 53/2018); y avaló la imposición de una asamblea constituyente antidemocrática (SC 378/2017; Brewer-Carías, 2016, pp. 91 y ss.; Hernández, 2016, pp. 51 y ss., y Casal, 2017b, pp. 161 y ss.).

Ciertamente, en mayo de 2017 la Sala Constitucional desconoció el alcance de los artículos 347 y 348 de la Constitución, al afirmar que el Presidente de la República tiene la facultad de convocar a una Asamblea Nacional Constituyente, sin que sea necesaria la previa expresión de la voluntad popular mediante referendo, a pesar de que de los referidos artículos, del principio de soberanía popular y del derecho a la participación política se desprende lo contrario (SC 378/2017; Brewer-Carías y García, 2017).

Al instalarse la espuria asamblea nacional constituyente, con una Sala Constitucional cuyo ropaje jurisdiccional estaba ya completamente deshilachado ante la virulencia de su potencia política e ideológica, aquella comenzó en parte a sustituirla y muchas de las decisiones extra ordinem que dicha Sala hubiera adoptado se desplazaron a ese pretendido cuerpo constituyente, una transición que se ha dado sin forzamientos, porque en el fondo ambos órganos han operado al margen del orden constitucional formalmente en vigor.

\section{IV.LOSELEMENTOS CONCEPTUALES Y LASESTRATEGIAS PROCESALES PUES- TOS AL SERVICIO DEL AUTORITARISMO EJECUTIVO Y JUDICIAL}

Conviene mencionar algunos de los basamentos conceptuales y herramientas procesales que han sido usados por la Sala Constitucional para demoler el Estado democrático y social de Derecho. Todos se apoyan en 
Esta revista forma parte del acervo de la Biblioteca Jurídica Virtual del Instituto de Investigaciones Jurídicas de la UNAM

la premisa de la ausencia de independencia judicial (Comisión Interamericana de Derechos Humanos, 2017). Esta falta de independencia, importa advertirlo, no es vista propiamente como un distanciamiento indeseable pero circunstancialmente explicable respecto de un cierto paradigma institucional, sino como una consecuencia de la concepción ínsita al fenómeno de poder personal o cupular e ideológicamente aglutinante característico de la actual dominación política.

La opinión acerca de la necesidad de revisar la separación de poderes expresada por quien fuera presidenta del Tribunal Supremo de Justicia; las posturas jurisprudenciales relativas a una supuesta obligación de concertación parlamentaria con el poder ejecutivo durante el procedimiento legislativo, en lo relativo a las implicaciones económico-financieras de los proyectos de ley, concebida como una subordinación de la tramitación legislativa a la aprobación ejecutiva; $y$, en general, el sobredimensionamiento del estatus y atribuciones del presidente de la República como jefe de Estado, así como las numerosas acciones y declaraciones institucionales de ese Tribunal o de sus integrantes que erigen al Presidente de la República en conductor de un proceso políticamente homogéneo y monolítico, ilustran que la idea del Estado de derecho es ajena e incluso contraria a los pilares axiológicos del régimen instaurado. De allí que la independencia judicial sea extraña al entramado ideológico y político-institucional del oficialismo.

Bajo esta constatación, paso apenas a enunciar algunas piezas teóricas y procesales del mecanismo autoritario empleado por la Sala Constitucional para desmantelar el Estado democrático de derecho.

\section{El postulado de la universalidad del control de constitucionalidad y de la garantía judicial de la Constitución como pretexto para la hipertrofia funcional}

En años previos a la aprobación de la Constitución de 1999 se consolidó una mentalidad favorable a la universalidad del control de constitucionalidad de las actuaciones u omisiones de los poderes del Estado y de la garantía judicial de la Constitución. Había que asegurar una protección judicial sin lagunas de la Constitución y los esfuerzos que se hicieran para ensanchar o replantear a esos efectos los instrumentos o principios procesales establecidos eran considerados plausibles. 
Esta revista forma parte del acervo de la Biblioteca Jurídica Virtual del Instituto de Investigaciones Jurídicas de la UNAM

Sobre estos cimientos colocó la Sala Constitucional muchos de sus primeros pronunciamientos, aprovechando además que comenzó a actuar sin que se hubiera dictado ni la Ley Orgánica del Tribunal Supremo de Justicia, que tardaría mucho en adoptarse, ni la Ley Orgánica de la Jurisdicción Constitucional, aún no sancionada. El sentido con el cual esta Sala utilizó esos fundamentos fue por supuesto distinto al que había animado su gestación, aunque faltó también en aquella comprensión dominante una conciencia sobre los límites que la jurisdicción constitucional también debe respetar en un Estado de Derecho, en cuanto a la debida consideración de las competencias normativamente atribuidas y de los espacios funcionales de los demás órganos constitucionales.

\section{Desvalorización de la positividad jurídica $y$ de las formas procesales}

En línea con lo anterior se encuentra la tendencia, bastante robusta igualmente al momento de la elaboración de la Constitución de 1999 y de la entrada en funcionamiento de la Sala Constitucional, a promover una interpretación y una metodología jurídica menos sujetas a las formulaciones legales y más abiertas a la determinación judicial de su sentido y finalidad y a la apreciación del impacto de los principios y valores constitucionales en la precisión de su significación jurídica (Molina, 2002, y Delgado, 2008). Esto estaba en consonancia con el reconocimiento y expansión de la fuerza normativa de la Constitución y la consecuente constitucionalización del ordenamiento jurídico y era también una reacción ante el formalismo jurídico que en parte había prevalecido en décadas anteriores.

Se trataba de una orientación en lo esencial justificada a la luz de la evolución de los estudios sobre la hermenéutica jurídica y de la formación del Estado constitucional de Derecho, aunque algunas visiones llegaron un poco lejos. Ello dio lugar a un estado de opinión con el cual podía sintonizar la Sala Constitucional, al apelar a la función de garantía de la supremacía constitucional para liberarse con facilidad de los parámetros constitucionales referidos al alcance de sus competencias y acometer una labor pretoriana de perfilamiento de su agigantado e indefinido campo de atribuciones. Esto se proyectó sobre el terreno sustantivo y sobre la interpretación de disposiciones constitucionales materiales, a veces en virtud 
Esta revista forma parte del acervo de la Biblioteca Jurídica Virtual del Instituto de Investigaciones Jurídicas de la UNAM

de la invocación del Estado democrático y social de derecho y de justicia, a lo cual luego se aludirá.

Algo similar ocurrió en relación con las formas procesales, lo cual estaba en continuidad con el pensamiento apuntado, pues el juez que, con la aparente autoridad de la Constitución, prescinde en su tarea interpretativa de la normatividad positiva, incluso de la constitucional, en atención a ciertos valores o fines, estaría también facultado para moldear las reglas procesales, con lo cual termina desconociendo el espacio democrático de la actividad del poder constituyente y del legislador.

\section{La invocación del Estado democrático y social}

de derecho y de Justicia para resquebrajar el ordenamiento constitucional y dar anclaje en la Constitución a un proyecto ideológico externo a ella

La Carta Fundamental de 1999 señala, en su artículo 2, que Venezuela se constituye en un Estado democrático y social de Derecho y de Justicia. Esta alusión a un Estado de Justicia ha sido aducida por la Sala Constitucional con el objeto de apuntalar interpretaciones apartadas de la regulación constitucional o legal en materia sustantiva y procesal. La noción de Estado de Justicia, y la de Estado social, han sido invocadas para debilitar las garantías del Estado de Derecho. En lugar de entender, como hubiera sido correcto, que ambos se insertan en un Estado de Derecho y lo presuponen, tales conceptos han sido utilizados para socavar el ordenamiento constitucional, al tomarlos aisladamente y con una perspectiva ideológica extraña al modelo del Estado social y democrático de Derecho. La apelación a la justicia en el artículo 2o. de la Constitución no ha de concebirse como un caballo de Troya capaz de desmontar la entera estructura constitucional, sino tiene que ser leída sistemáticamente dentro de la Constitución y de la fórmula global del Estado democrático y social de derecho en que se inscribe. Sin embargo, la Sala Constitucional ha seguido otro camino y ha acudido al artículo 2o. a fin de justificar soluciones jurisprudenciales lesivas de reglas o principios constitucionales (Berríos, 2013, pp. 21 y ss., y Petit, 2017, 16 y ss.).

Especialmente grave es que esta fórmula haya sido calificada como la consagración constitucional de un proyecto político o ideológico específico, cuyos contornos no se delimitan jurídicamente ni con base en precep- 
Esta revista forma parte del acervo de la Biblioteca Jurídica Virtual del Instituto de Investigaciones Jurídicas de la UNAM

tos constitucionales, sino de acuerdo con la "tradición de cultura viva" y un "análisis concreto e histórico de los valores compartidos por el pueblo venezolano" (SC 1309/2001). Entre los componentes de este proyecto político subyacente a la Constitución y que cristalizaría en el citado artículo 2o. se encuentra el rechazo al racionalismo individualista, a la afirmación de valores universales y a la primacía del derecho internacional, lo cual se ha traducido, entre otras construcciones jurisprudenciales, en la prevalencia abstracta o apriorística de derechos o intereses colectivos sobre derechos fundamentales y en la reconducción y vaciamiento, en clave nacionalista o soberanista, de las disposiciones constitucionales de apertura a la protección internacional de los derechos humanos (Ayala, 2010, pp. 85 y ss.).

\section{La superioridad apriorística de los intereses calificados de colectivos sobre los derechos individuales}

La Sala Constitucional ha roto el equilibrio existente, como punto de partida, entre los bienes constitucionales, al conferir a derechos o intereses pretendidamente colectivos una primacía abstracta o automática sobre los derechos individuales, aun cuando tengan la condición de derechos fundamentales (SC 1265/2008; Casal, 2010b, 173 y ss.). Con apelación a la fórmula del Estado social de derecho y de Justicia o sin ella, la jurisprudencia constitucional aborda las situaciones de colisiones entre bienes constitucionales bajo la premisa de que los de índole colectiva prevalecen siempre sobre los individuales. Más aún, ha rechazado, incluso como máxima metodológica, la idea de que la libertad es la regla y su restricción la excepción. Los derechos usualmente denominados sociales vencen de esta forma apriorísticamente sobre derechos fundamentales, dejando de lado las pautas que deberían orientar en las circunstancias particulares una ponderación de acuerdo con la exigencia de la concordancia práctica y el principio de proporcionalidad. La etiqueta de lo social o colectivo es así un talismán invocado por el gobierno que oscurece el análisis y doblega cualquier resistencia jurídica a las implicaciones de los programas que implementa en materia de vivienda, de acceso a las tierras agrícolas, de protección al consumidor o de lucha contra ciertas infracciones o delitos, sin importar que sean menospreciados el derecho de propiedad, la libertad económica u otros derechos fundamentales.

Cuestiones Constitucionales, Núm. 44, Enero-Junio 2021

ISSN: $2448-4881$ 
Esta revista forma parte del acervo de la Biblioteca Jurídica Virtual del Instituto de Investigaciones Jurídicas de la UNAM

Esta orientación jurisprudencial no ha llevado consigo, importa aclararlo, una amplia tutela judicial de los derechos sociales o prestacionales. Por el contrario, en comparación con países latinoamericanos como Colombia o Perú, esta protección jurisdiccional ha sido modesta, porque el régimen entiende que corresponde esencialmente al poder ejecutivo el desarrollo de la política social, sin sujeción al principio de legalidad ni a un control judicial efectivo.

\section{LA JURISDICCIÓN CONSTITUCIONAL DE LA REDEMOCRATIZACIÓN}

Son múltiples los aspectos en los cuales se precisa de una nueva jurisdicción constitucional. Los cambios que deben ser introducidos no con simples modificaciones regulativas u organizativas, ya que se requiere de un verdadero giro copernicano en la jurisdicción constitucional, afincado sobre todo en los criterios de fondo que guían la labor jurisdiccional y en la concepción referida a los poderes y límites de la jurisdicción constitucional y al sistema de justicia constitucional, lo cual puede naturalmente llevar aparejadas reformas en el diseño institucional. Los asuntos organizativos de la jurisdicción constitucional no serán tratados aquí, pero conviene dejar apuntada la relevancia del procedimiento de selección de los magistrados constitucionales, que ha sido abordado en otros estudios como los de Fix-Zamudio y Astudillo (2013) y Casal (2017c, pp. 154 y ss.).

\section{Las atribuciones del órgano encargado de la jurisdicción} constitucional y la recuperación del sistema de justicia constitucional

La nueva jurisdicción constitucional tendrá a su cargo la gran responsabilidad de contribuir a levantar desde sus cimientos una genuina institucionalidad democrática. Más aún, le corresponderá desmontar maneras de razonar judicialmente y de interpretar la Constitución. Muchas doctrinas sentadas por la Sala Constitucional del Tribunal Supremo de Justicia durante estos años han sido objeto de cuestionamiento generalizado y su refutación y sustitución forman parte de la agenda de la jurisdicción constitucional de la democracia y el Estado social de derecho. Pero junto a ello es indispensable concebir de otro modo el papel del juez constitucional y sus mecanismos de actuación. 
Esta revista forma parte del acervo de la Biblioteca Jurídica Virtual del Instituto de Investigaciones Jurídicas de la UNAM

De la exaltación de la que fue llamada la super sala y del carácter omnicomprensivo del control de constitucionalidad, sobre la cual se instaló la Sala constitucional autoritaria, ha de pasarse a una conciencia acendrada sobre la necesidad de focalizar la jurisdicción constitucional en los temas medulares del constitucionalismo y de someterla al orden y legalidad procesales. Al mismo tiempo, los desmanes de este ciclo político y judicial han demostrado que un exceso o desviación de la justicia constitucional se traduce en desequilibrios que menoscaban los controles y contrapesos institucionales. El ecosistema democrático-constitucional se resiente cuando una jurisdicción constitucional sobredimensionada competencialmente interviene prematuramente ante situaciones que aún deben permanecer en el campo de decisión de espacios democráticos, así como resulta afectada la autonomía individual o social cuando aquella no reconoce los linderos entre los asuntos públicos y los de desarrollo personal o participación ciudadana amparados por derechos fundamentales.

La Sala Constitucional ha tergiversado ciertamente la finalidad y alcance de los generosos instrumentos y facultades procesales que la Constitución le confiere para su garantía, pero lo que se intenta apuntar es que, siendo aquel el principal problema, hay otro solapado consistente en equiparar la magnitud de los poderes judiciales con la efectividad y la idoneidad material de la jurisdicción constitucional. Las regulaciones procesales deben ser sin duda suficientes para que el sistema de justicia constitucional resguarde la Constitución, pero la clave radica en cómo se utilicen los mecanismos procesales disponibles, desde el punto de vista de la consideración que se tenga por la función de los otros órganos constitucionales y de los criterios sustantivos que orienten la jurisprudencia.

Es importante asimismo que el tribunal o sala constitucional actúe con base en competencias constitucional y legalmente establecidas y no como un demiurgo jurídico que determina según los hechos que se presenten la vía procesal y el procedimiento aplicable, si es que se somete a alguno. Puede haber márgenes para la identificación de poderes implícitos y de cierta autonomía procesal, pero no es aceptable que el postulado o máxima sea el de la omnipotencia de la jurisdicción constitucional.

La degradación de estos años ha llegado a tal punto que se prescinde hasta del derecho al debido proceso, pues al conocer de solicitudes de revisión de sentencias, de recursos de interpretación directa de la Constitución e incluso de acciones de nulidad la Sala Constitucional resuelve el fondo o mérito de controversias referidas a derechos individuales o a atribuciones 
Esta revista forma parte del acervo de la Biblioteca Jurídica Virtual del Instituto de Investigaciones Jurídicas de la UNAM

constitucionales de órganos del poder público sin procedimiento contradictorio alguno y al margen de los cauces procesalmente previstos (SC 207/2014, 9/2016, 473/2016, 478/2016, 797/2016, 1086/2016, 2/2017 y 156/2017). La Sala Constitucional terminó abdicando, finalmente, de su condición de órgano jurisdiccional y sus integrantes renegaron con sus ejecutorias del oficio del juez. Ello sin entrar a examinar los graves vicios en la composición de esa y de las demás Salas del Tribunal Supremo de Justicia, que se cometieron, primero, con motivo de la ampliación abusiva del número de sus miembros en el 2004 y, luego, cuando se produjo la designación de magistrados principales y suplentes al margen de la Constitución y de la ley respectiva, en diciembre de 2015.

Requerimos de una jurisdicción vigorosa en la defensa de la libertad, de los espacios de libre participación democrática y de los controles intra e interorgánicos, y por eso, convencida de la significación de los límites a los que ella misma debe quedar sujeta.

El desbordamiento competencial de la Sala Constitucional ha tenido consecuencias en sus relaciones con el legislador y con los jueces ordinarios. En relación con esto último es indispensable observar que dicha Sala ha minimizado el rol de los demás tribunales de la República en la garantía de la integridad y en la interpretación de la Constitución y, en particular, en el ejercicio del control difuso de la constitucionalidad. El artículo 335 de la Constitución ha sido adulterado en su significación y ha sido usado por esta Sala para fijar interpretaciones constitucionales vinculantes que no guardan conexión con la resolución de causas específicas ni con los cauces procesales normativamente establecidos. Además, estas (re) lecturas de la Constitución se imponen rígidamente a la judicatura e incluso al legislador, de tal manera que se niega a aquella las facultades de adaptación o distinción ínsitas a la aplicación de precedentes, o se admiten muy limitadamente; y se cercenan, en relación con el segundo, sus potestades de configuración político-normativa (Urosa, 2009 y Casal, 2017c).

Debe racionalizarse y acotarse el alcance del efecto vinculante de las interpretaciones constitucionales de la instancia responsable de la jurisdicción constitucional, sujetándola a la lógica del precedente (Landa, 2010, pp. 193 y ss.) y promoviendo dinámicas plurales y progresivas de construcción de la jurisprudencia constitucional, con participación relevante de los jueces ordinarios. Han de reconocerse, por otro lado, las peculiaridades de la incidencia de tales interpretaciones sobre el legislador. 
Esta revista forma parte del acervo de la Biblioteca Jurídica Virtual del Instituto de Investigaciones Jurídicas de la UNAM

Lo dicho conduce a insistir en la necesidad de preservar el carácter mixto o integral de nuestro sistema de justicia constitucional, menoscabado por la voracidad competencial de la Sala Constitucional. Un poder judicial restructurado con base en los principios del mérito y de la carrera judicial, deberá desempeñar una función capital en la garantía e interpretación de la Constitución y también en el ejercicio del control difuso de la constitucionalidad de las leyes, y el órgano de jurisdicción constitucional deberá impulsar, no restringir, esas iniciativas judiciales, todo ello sin perjuicio de las facultades que ostente para sentar una última palabra en el orden jurisdiccional, por cauces procesales específicos, a fin de salvaguardar la seguridad jurídica y la uniformidad en la interpretación constitucional, o la protección de derechos fundamentales en supuestos de grave desconocimiento.

En lo procesal habría que rechazar, principalmente: el acortamiento de las competencias de los jueces ordinarios en materia de control difuso de la constitucionalidad de las leyes, al haber sido limitadas al examen de la contradicción explícita o literal entre disposiciones legales y preceptos constitucionales; la expansión indebida de la facultad de la Sala Constitucional de revisar las sentencias de otros tribunales de la República, sin sujeción además al debido proceso ni a plazo alguno para su ejercicio; la tergiversación del sentido y alcance del efecto vinculante de las interpretaciones de la Constitución establecidas por dicha Sala, para reconducirlo a la dinámica de los precedentes y de la construcción plural de la jurisprudencia; el avocamiento de causas en trámite en otros órganos judiciales, ordenado por la Sala Constitucional, o por otras Salas del Tribunal Supremo de Justicia en el ámbito material respectivo, lesivo del derecho al juez natural, que debería suprimirse; la solicitud directa de interpretación constitucional, como mecanismo usado para reescribir la Constitución o dirimir subrepticiamente controversias subjetivas bajo el manto del carácter abstracto del asunto, que debería ser eliminada o redefinida restrictivamente; $y$, en suma, la potestad que esa Sala se ha atribuido para admitir toda clase de pretensiones relacionadas con la pretendida garantía de la Constitución, sin sometimientos a pautas legislativas ni procedimentales (Herrera, 2008, pp. 7 y ss.; Haro, 2000, pp. 455 y 456, y Villegas, 2000, pp. 417 y ss.). 
Esta revista forma parte del acervo de la Biblioteca Jurídica Virtual del Instituto de Investigaciones Jurídicas de la UNAM

\section{Los nuevos paradigmas sustantivos de la jurisprudencia constitucional}

Como se colige de lo hasta ahora afirmado, la transformación primordial de la jurisdicción constitucional se conecta con los criterios sustantivos y la misión institucional que han de orientar su desempeño. Conviene subrayar que, si bien los tribunales o salas constitucionales pueden contribuir a la estabilidad institucional, no es este el aspecto cardinal de sus funciones $\mathrm{o}$, en otras palabras, el específico aporte de la jurisdicción constitucional a ese propósito es el que la distingue. El ethos o finalidad primordial de esta jurisdicción se encuentra no en el mantenimiento del orden público o en el sometimiento del pueblo al poder establecido, sino principalmente en la preservación de espacios de libertad que permitan el desarrollo de las potencialidades humanas, la actuación de las minorías y la fluidez del proceso democrático.

La primera tarea de la jurisdicción constitucional será revertir los criterios jurisprudenciales sentados por la Sala Constitucional que resultan abiertamente contrarios al constitucionalismo y al principio democrático, lo cual comprende no solo los contenidos en sentencias cuyo dispositivo comporte violaciones a derechos humanos o a reglas o principios constitucionales fundamentales desde la óptica apuntada, sino también los que han sentado el basamento teórico para el andamiaje judicial autoritario, aunque no hayan sido determinantes para la resolución del caso concreto. Estas (seudo) interpretaciones deberán ser rechazadas y reemplazadas por otras conformes con la democracia constitucional. Podría incluso acudirse al artículo 25 de la Constitución, o a los principios jurídicos en que se sustenta, para admitir acciones dirigidas a declarar la nulidad absoluta de las sentencias dictadas en violación manifiesta de los derechos humanos. Más aún, dado que tales decisiones emanaron de un órgano político, que simuló la condición de jurisdiccional para disolver los pilares de la institucionalidad democrática, dichas pretendidas sentencias podrían ser calificadas como inexistentes por no haber sido dictadas por un órgano judicial. Luego se ahondará en los instrumentos procesales disponibles a estos efectos.

Por unas u otras vías procesales habrá que desmontar criterios de la Sala Constitucional referidos a los siguientes asuntos, que se mencionan a título puramente enunciativo. Habría que desechar: la inversión del propósito del artículo 23 de la Constitución para eximir a la Sala Constitucional y al Estado venezolano de cualquier control internacional en materia 
Esta revista forma parte del acervo de la Biblioteca Jurídica Virtual del Instituto de Investigaciones Jurídicas de la UNAM

de derechos humanos (SC 1942/2003) y declarar inejecutables sentencias de la Corte Interamericana de Derechos Humanos (SC 1939/2008 y 1547/2011); la desnaturalización del concepto de delitos de lesa humanidad (SC 1712/2001); la mutilación del artículo 42 de la Constitución para viabilizar inhabilitaciones políticas que no se fundan en una sentencia penal condenatoria (SC 1265/2008); el cercenamiento del derecho a la libre manifestación, al haberlo supeditado a la solicitud y emisión de una autorización previa (SC 276/2014); la conversión por sentencia de la Sala Constitucional en juez penal, infringiendo el principio de la legalidad, el derecho al juez natural y el debido proceso (SC 245/2014 y 263/2014); el ensanchamiento de la noción de flagrancia para justificar privaciones policiales ilegítimas de la libertad (SC 2580/2001); el desconocimiento de la libertad de asociación y del derecho a la libre participación política que supone fijar jurisprudencialmente requisitos internos de organización a las asociaciones sociales que aspiren actuar por medio de cauces institucionales de protagonismo ciudadano (SC 656/2000); la habilitación al Consejo Nacional Electoral, al margen de la Constitución, para regular el derecho político a cumplir la iniciativa popular de los referendos, como exigencia indispensable para la operatividad de ese derecho, lo cual sería aprovechado, con aquiescencia de la Sala Constitucional, para fijar barreras casi infranqueables (SC 2073/2003); la admisión de supuestos de censura judicial y, en general, la imposición de condicionantes previos al ejercicio del derecho de libertad de expresión y de pautas obligatorias, judicialmente reclamables, sobre la línea editorial o el equilibrio informativo de los medios de comunicación (SC 1013/2001 y 1049/2009); la devaluación de la libertad económica y demás derechos fundamentales al plano de un punto de vista que concurre en una ponderación abierta de bienes jurídicos y la relativización de la reserva legal en esa y otras materias (SC 1613/2004); la afirmación de la prevalencia apriorística de los derechos calificados como colectivos sobre los derechos individuales; el uso de la categoría del Estado social para prescribir como constitucionalmente necesarios componentes o concepciones propias de la ideología socialista; el empleo de la idea del Estado de Derecho y de Justicia para socavar el primero; la negación de los riesgos que la reelección indefinida supone para la institucionalidad democrática en nuestro sistema presidencial (SC 1488/2006); la aceptación de los decretos leyes orgánicos y de leyes habilitantes en toda clase de materias y de índole indeterminada (SC 1716/2001); la cons- 
Esta revista forma parte del acervo de la Biblioteca Jurídica Virtual del Instituto de Investigaciones Jurídicas de la UNAM

trucción de la doctrina aberrante del supuesto desacato de la Asamblea Nacional como causa general invalidante de su actuación (SC 3/2016 y 808/2016); la centralización de competencias constitucionales exclusivas de los Estados y la convalidación de elementos del Estado comunal (SC 565/2008 y 355/2017); la supresión de la atribución constitucional de la Asamblea Nacional de aprobar o improbar (con eficacia jurídica no solo política) la declaración de los estados de excepción y de su prórroga (SC 7/2016); y el otorgamiento al Presidente de la República de la facultad de instalar una asamblea nacional constituyente, previa formulación por él mismo de las reglas de elección de sus integrantes, sin que el pueblo se hubiera pronunciado al respecto en referendo (SC 378/2017), entre otros pronunciamientos arbitrarios (Ayala, 2010, pp. 85 y ss.; Brewer-Carías, 2007, pp. 231 y ss. y 2001, pp. 17 y ss.; Casal, 2005, pp. 316 y ss.; Sánchez, 2017; Canova y Herrera, 2009).

Esta es solo una muestra del trabajo que la jurisdicción constitucional de la democracia deberá llevar a cabo. Colosal por la extensión de las materias en que se han establecido en estos años postulados contrarios a la libertad y a la separación de poderes, pero que puede ponerse en escena rápidamente, haciendo explícita desde las primeras decisiones la savia nueva de la justicia que vivifique las estructuras constitucionales.

\section{Algunas herramientas relevantes para impulsar el nuevo perfil institucional}

Son muchas las estrategias jurisdiccionales que podrían implementarse desde una jurisdicción constitucional renovada a fin de facilitar la adopción de las orientaciones procesales y de los criterios sustantivos antes expuestos. Ahora se aludirá solamente, a título ilustrativo, a algunas de ellas. El denominador común estriba en la identificación de tipos de fallos, modalidades del discurso y mecanismos judiciales que pueden ser de especial utilidad para convertir a la jurisdicción constitucional en actor fundamental de la democratización. Además, se hará referencia a obligaciones e instituciones internacionales que apuntan en la misma dirección.

En primer lugar, ha de tenerse presente que las sentencias que se emitan en la fase de transición a la democracia deben tener un carácter aleccionador o pedagógico. No deben conformarse con la resolución de una controversia concreta, sin duda el aspecto esencial de la tarea jurisdiccional, 
Esta revista forma parte del acervo de la Biblioteca Jurídica Virtual del Instituto de Investigaciones Jurídicas de la UNAM

sino que la forma en que aquella es dirimida y las consideraciones que al hacerlo se pronuncien deben llevar y hacer visible la impronta de la recta administración de la justicia y de la apertura de espacios democráticos para el disenso, la participación ciudadana y la inclusión de los diversos actores políticos y sociales. En particular, tales decisiones han de llevar el sello de la garantía de los derechos inherentes a la persona, como fundamento de legitimación filosófico-política de la autoridad estatal. La libertad y la dignidad del ser humano trazan límites al ejercicio del poder público que la jurisdicción constitucional debe enfatizar, especialmente cuando se ha vivido un proceso de sujeción arbitraria de sus derechos básicos a los intereses gubernamentales y de negación de su autonomía individual, en virtud de la estatización o regulación abusiva de muchas esferas de la actividad económica, del manejo clientelar de programas sociales y de la imposición de una ideología. La experiencia comparada antes esbozada enseña que los tribunales constitucionales pueden motorizar un replanteamiento conceptual que coloque a la persona, sus derechos y su libertad en el centro del sistema constitucional (Häberle, 2004, pp. 323 y ss.). No en el sentido de que tales tribunales o los jueces constitucionales pretendan hacer valer jurisprudencialmente sus propias convicciones o las visiones políticas predominantes tras el cambio de régimen. Se trata más bien de segar con los instrumentos de la jurisdicción constitucional la maraña de criterios autoritarios y de postulados ideológicos que se apoderaron del espacio público de deliberación racional para suprimir el pluralismo y que sometieron al ser humano a una creciente vulnerabilidad en la titularidad y goce de derechos civiles, políticos, económicos y socioculturales, a fin de subyugarlo y de despojarlo de la fuerza cívica necesaria para arrostrar excesos gubernamentales.

De allí que sea importante preguntarse acerca de la clase de sentencias que sería aconsejable emplear en esa etapa. En consonancia con lo afirmado, el discurso constitucional, que tiende a diferenciarse del que es habitual en los procesos ordinarios (Ferreres, 2009, pp. 36 y ss.), ha de ser construido teniendo en cuenta el auditorio de la sociedad democrática al que también deben estar dirigidos los pronunciamientos de la Sala Constitucional. Preservando el rigor de la argumentación jurídica, componente indispensable de la legitimidad de su obrar (Möllers, 2011, pp. 281 y ss.), la jurisdicción constitucional ha de abrir el lenguaje para acceder a un público más amplio que el de los expertos constitucionalistas, de manera que se pongan de relieve, cuando corresponda, los principios democráticos y

Cuestiones Constitucionales, Núm. 44, Enero-Junio 2021

ISSN: 2448-4881 
Esta revista forma parte del acervo de la Biblioteca Jurídica Virtual del Instituto de Investigaciones Jurídicas de la UNAM

del Estado de Derecho que sustentan las decisiones adoptadas, así como la significación de los derechos humanos protegidos. Esta contribución a la promoción de una cultura de la democracia constitucional es primordial para una sólida democratización. Lo dicho presupone que el proceso constitucional esté igualmente permeado por las voces diversas del pluralismo político, social y cultural. La celebración de audiencias públicas, las oportunidades para la presentación de amicus curiae, e incluso la disposición a incorporar al proceso las opiniones de expertos referidas a las bases fácticas o empíricas de la medida controvertida son recomendables a los fines indicados.

La jurisdicción constitucional deberá no sólo asumir un talante y un comportamiento diferente respecto de los asuntos que sean sometidos a su conocimiento en la etapa de recuperación institucional, sino que está obligada a enfrentar rémoras o paradigmas del pasado autoritario. Así como lo hizo la Corte Constitucional italiana en su etapa inaugural respecto de leyes del fascismo, lo cual le ayudó a obtener autoridad (Bogdandy y Paris, 2019, pp. 5 y ss.), la jurisdicción constitucional venezolana ha de derribar los pilares del derecho antidemocrático que rigió durante varios años, lo cual se proyecta sobre la legislación, los decretos leyes y los pronunciamientos judiciales. En relación con estos últimos, un mecanismo que ha sido desarrollado por la Corte Constitucional colombiana, en circunstancias de normalidad, y que sería de provecho para la transición venezolana es la declaración de la nulidad de sentencias proferidas por la propia Corte. Bajo causales muy estrictas, sumamente excepcionales, esta se considera facultada para declarar la nulidad de sus decisiones de revisión de las tutelas dictadas por los tribunales, pese a que normativamente se prevé que contra las sentencias de la Corte Constitucional no procede recurso alguno. Aunque esta última es todavía la regla general, jurisprudencialmente ha sido creado el "incidente extraordinario de nulidad" (SU116/18) que es posible plantear ante la propia Corte, dentro del breve plazo y demás condiciones de forma y de fondo establecidas. Cierta analogía con este mecanismo guarda la decisión de la Corte de Constitucionalidad de Guatemala (expediente 2395/2006) de determinar la ausencia de efecto jurisprudencial vinculante o de precedente de lo dispuesto en una sentencia abiertamente inconstitucional previamente emitida por ella misma, la cual sin embargo no fue anulada.

Mutatis mutandis cabría acudir a una solución procesal similar en Venezuela, en relación con sentencias de la Sala Constitucional que hayan 
Esta revista forma parte del acervo de la Biblioteca Jurídica Virtual del Instituto de Investigaciones Jurídicas de la UNAM

socavado, adulterado o demolido, todo ello ha sucedido, elementos esenciales de la institucionalidad democrática — reflejados en el artículo 30. de la Carta Democrática Interamericana - y cuya eventual pervivencia en el orden democrático-constitucional por emerger debe ser explícita y razonadamente rechazada, en la forma discursiva antes señalada. Pienso en decisiones como las referidas en el apartado anterior. Las causales serían, pues, distintas, y mucho más graves, pues versarían no sobre serias violaciones al debido proceso $u$ otras semejantes en las que aisladamente incurra un tribunal constitucional, en un marco institucional democrático, sino a supuestos extraordinarios en los que la misma Sala Constitucional, como órgano, ha sido protagonista del desmantelamiento de ese marco. El contenido de tales decisiones autoritarias y su origen en actuaciones no merecen el calificativo de jurisdiccionales, como tampoco la instancia de la cual emanan, pues el mismo Tribunal Supremo de Justicia, del cual la Sala Constitucional forma parte, ha sido integrado vulnerando abiertamente las normas constitucionales.; siendo así, se aconseja hablar en estos casos de una acción o incidente de declaración de inexistencia de la sentencia. Por otra parte, la Sala Constitucional puede servirse en una fase inicial, con garantía del debido proceso, de la facultad de revisión de sentencias, cuando se trata de situaciones también graves y excepcionales vinculadas con decisiones firmes de otras Salas del Tribunal Supremo de Justicia o de tribunales ordinarios.

En este contexto de regeneración jurisprudencial puede ser también plausible propugnar un reconocimiento y desarrollo de los precedentes que reivindiquen el estándar más alto de garantía de derechos fijado por la jurisprudencia constitucional, bajo una lectura dinámica de la misma, como se ha aceptado en algunos sistemas. Esta la doctrina sentada por el Tribunal Constitucional Plurinacional de Bolivia, recogida entre otras en la sentencia 0015/2018-S4.2 De este modo sería posible remontarse incluso a criterios de la antigua Corte Suprema de Justicia, cuando tengan aquella condición o contribuyan a la formación del estándar, con el fin de subrayar la perspectiva de acumulación histórica en el forjamiento de la democracia, sin perjuicio de que sobre esas bases se edifiquen otras interpretaciones o elaboraciones conceptuales.

Finalmente, una institución llamada a adquirir una significación estelar en la reconstrucción democrática es el control de convencionalidad y, en general, la apertura a la protección internacional de los derechos humanos. El sistema interamericano ha jugado un papel notable en procesos 
Esta revista forma parte del acervo de la Biblioteca Jurídica Virtual del Instituto de Investigaciones Jurídicas de la UNAM

de restablecimiento democrático, ya que la observancia de las decisiones ya dictadas por los órganos internacionales correspondientes y pendientes de aplicación implica de entrada un reacomodo institucional que, junto a los distintos medios de reparación de las violaciones a derechos humanos perpetradas, marca la evolución ulterior de los acontecimientos (García Belaúnde y Eguiguren, 2008, pp. 371 y ss.). En el caso venezolano, como en otros países de la región, la degeneración autoritaria se ha traducido en la resistencia a cualquier modalidad eficaz de control o limitación del poder gubernamental, lo cual condujo prontamente a la desatención o inejecución de las sentencias de la Corte Interamericana de Derechos Humanos y luego a la ruptura con el sistema y a la denuncia de la Convención Americana sobre Derechos Humanos. La recuperación de la democracia debe llevar al inmediato cumplimiento de las recomendaciones de la Comisión Interamericana o de las decisiones de la Corte Interamericana que han sido ignoradas, al igual que de los informes u observaciones de otros organismos internacionales competentes en materia de derechos humanos, y la jurisdicción constitucional puede ganar autoridad comprometiéndose desde el principio con la plena reinserción de Venezuela en el sistema interamericano. No es este el lugar para analizar los caminos que han de seguirse para lograr esa reinserción, sin perjuicio de que esta puede ser favorecida por una Sala Constitucional renovada.

Lamentablemente este órgano se ha apartado de su misión constitucional y ha terminado invocando los derechos humanos para socavar el Estado democrático de derecho.

Lo que se quiere subrayar es que la jurisdicción constitucional ha de empeñarse en el pronto y pleno cumplimiento de decisiones hasta ahora soslayadas y ha de robustecer su propia posición institucional en la garantía de los derechos humanos impulsando o exigiendo las reformas indispensables en el ámbito de la carrera judicial e involucrándose en la implementación de sentencia de la Corte Interamericana en este y en los demás asuntos referidos a Venezuela que han sido abordados por la jurisprudencia interamericana. Su participación en el control de convencionalidad y en el diálogo jurisdiccional es también otra tarea altamente promisoria. 
Esta revista forma parte del acervo de la Biblioteca Jurídica Virtual del Instituto de Investigaciones Jurídicas de la UNAM

\section{CONCLUSIÓN}

La actuación de la Sala Constitucional del Tribunal Supremo de Justicia, desde su creación y más aún en los últimos años, demuestra los daños institucionales que puede ocasionar la instrumentalización de la justicia por la política o, en otras palabras, la falta de independencia judicial y la colonización de la jurisdicción constitucional por una hegemonía ideológica o de partido. Esto conduce a una reflexión sobre la importancia de diseñar mecanismos institucionales y barreras sociales y culturales ante las amenazas de ocupación de la institucionalidad por liderazgos o proyectos políticos que por definición estén cerrados a la alternancia, esto es, a la aceptación y conservación del marco constitucional dentro del cual se produce un pendulamiento de ofertas electorales y programas de gobierno. Es esencial preservar el pluralismo político y social, es decir, el espacio común para la confrontación democrática entre distintas organizaciones y propuestas políticas y la multiplicidad de grupos y asociaciones intermedias entre el Estado y el individuo que, en conexión con el ejercicio de la ciudadanía, influyen en el poder público y a la vez lo condicionan. Más allá de la apelación genérica a la separación de poderes y a la significación de los controles interorgánicos e intraorgánicos, es necesario levantar un inventario de soluciones específicas probadas en sistemas democráticos que hayan funcionado como factores efectivos de contención de posibles desviaciones autoritarias, así como de las que cabría adoptar frente a un proceso de esta índole que, a pesar de tales cautelas, ya haya comenzado. La propia configuración orgánica y competencial de la jurisdicción constitucional ha de ser repensada en este contexto. Adicionalmente, hay que sembrar o fortalecer iniciativas sociales y económicas que favorezcan la capacidad de respuesta de la persona ante tales peligros.

Esto debe ir acompañado de la consolidación de una cultura de la democracia y el Estado de Derecho. Es preciso superar la idea, muy extendida en países latinoamericanos, de que quienes ganan las elecciones pasan a ser dueños de todos los asuntos políticamente relevantes $\mathrm{y}$, en tal condición, colocan acólitos en las instituciones llamadas constitucionalmente a cumplir labores de control. Los pesos o contrapesos requeridos por el Estado de derecho solo son posibles si se acepta la legitimidad del poder de los cuerpos judiciales y de la jurisdicción constitucional, con el alcance que esta posea en cada ordenamiento, cuya fuente o fundamento se encuentra 
Esta revista forma parte del acervo de la Biblioteca Jurídica Virtual del Instituto de Investigaciones Jurídicas de la UNAM

no propiamente en el sufragio y las elecciones, sino principalmente en la adecuada resolución de los conflictos con base en el derecho y la argumentación racional. En lo que concierne a esa jurisdicción, es ciertamente primordial que se mantenga su vinculación con la dinámica democrática, mediante el procedimiento de designación de los jueces constitucionales y otros medios, pero esto no debe llevar a menoscabar la identidad de su función jurisdiccional, que solo podrá ser desempeñada si se respeta escrupulosamente la independencia judicial, se realiza la selección con base principalmente en la calificación profesional o académica demostrada y se promueven las virtudes del oficio del juez. No hay alternativa para los sistemas de justicia constitucional: o se propugna la independencia del poder judicial en general y de la jurisdicción constitucional en particular, con el afianzamiento de la conexión democrática que respecto de esta sea necesario, o se niega un espacio autónomo y significativo para el derecho y para el control judicial del poder gubernamental, caso en el cual los tribunales o salas constitucionales serán actores protagónicos y quizás innovadores de esa dominación política, simples reproductores de los dictados del régimen imperante, o instancias pasivas que dejan hacer creyendo falsamente que con ello se aminora su responsabilidad respecto de los desafueros que puedan cometerse.

\section{FUENTES CONSULTADAS}

Asamblea General de la Organización de Estados Americanos (2019). Resolución sobre "La situación de Venezuela y la crisis de migrantes venezolanos", del 28 de junio de 2019, disponible en https://www.oas. org/es/centro_noticias/comunicado_prensa.asp? sCodigo=D-013/19 (consulta: 20-08-2019).

AyAla CORAO, C. (2010). "La doctrina de la inejecución de las sentencias internacionales en la jurisprudencia constitucional de Venezuela (19992009)", en Bogdandy, A. V., Ferrer MaC-Gregor, E. y Morales ANTONIAZZI, M. (coord.), La justicia constitucional y su internacionalización. ¿Hacia un Ius Constitutionale Commune en América Latina? T. II. México: IIJ-UNAM/Max-Planck-Institut für ausländisches öffentliches Recht und Völkerrecht. 
Esta revista forma parte del acervo de la Biblioteca Jurídica Virtual del Instituto de Investigaciones Jurídicas de la UNAM

BAZÁN, V. y NASH, C. (ed.) (2011). Justicia constitucional y derechos fundamentales. Fuerza normativa de la Constitución. Montevideo: Konrad Adenauer Stiftung.

Berríos OrtigozA, J. (2013). "El concepto constitucional de Estado democrático y social de Derecho y de Justicia como parámetro interpretativo del poder coercitivo de la administración pública en Venezuela", La justicia constitucional y la justicia administrativa como garantes de los derechos humanos reconocidos en la Constitución, III Congreso de Derecho Procesal Constitucional y I Congreso de Derecho Administrativo, en homenaje al Dr. Gonzalo Pérez Luciani, Caracas: FUNEDAUniversidad Monteávila.

BogdAndy, A. V. y PARIS, D. (2019). "La construcción de la autoridad judicial: una comparación entre la Corte Constitucional italiana y el Tribunal Constitucional Federal alemán”. Revista Derecho del Estado. núm. 43.

Boulanger, C. (2013). Hüten, richten, gründen: Rollen der Verfassungsgerichte in der Demokratisierung Deutschlands und Ungarns. Berlín: Epubli.

BREWER-CARÍAS, A. et al. (2001). La libertad de expresión amenazada, Caracas/San José: Editorial Jurídica Venezolana/Instituto Interamericano de Derechos Humanos.

BREWER-CARIAS, A. (2007). Crónica sobre la "in" justicia constitucional. La Sala Constitucional y el autoritarismo en Venezuela. Caracas, Editorial Jurídica Venezolana.

BREWER-CARÍAS, A. (2010). "La justicia constitucional como garantía de la Constitución", en Bogdandy, A. V., FERrer MaC-Gregor, E. y Morales ANTONIAZZI, M. (Coord.), La justicia constitucional y su internacionalización. ¿Hacia un Ius Constitutionale Commune en América Latina? T. I; México: IIJ-UNAM/Max-Planck-Institut für ausländisches öffentliches Recht und Völkerrecht.

BREWER-CARÍAS, A. (2016). Dictadura judicial y perversión del Estado de derecho, Caracas, Editorial Jurídica Venezolana.

BREWER-CARÍAS, A. y GARCÍA Soto, C. (coord.) (2017). Estudios sobre la Asamblea Nacional Constituyente y su inconstitucional convocatoria en 2017, Caracas-Bogotá: Editorial Jurídica Venezolana-Temis. 
Esta revista forma parte del acervo de la Biblioteca Jurídica Virtual del Instituto de Investigaciones Jurídicas de la UNAM

CAnova, A. y Herrera Orellana, L. (2009). ¿Expropiaciones o Vias de hecho? (La degradación continuada del derecho fundamental de propiedad en la Venezuela actual). Caracas, FUNEDA/UCAB.

Canova, A., Herrera Orellana, L., Rodríguez Ortega, R. y GratEROL STEFANELLI, G. (2014). El TSJ al servicio de la Revolución. Caracas: Editorial Galipán.

Casal, J. M. (2000). Constitución y Justicia Constitucional, Caracas, UCAB.

CASAL, J. M. (2005). Los actuales desafios de la justicia constitucional en Venezuela, en Estado de derecho, administración de justicia y derechos humanos (XXX Jornadas Domínguez Escovar). Barquisimeto, IEJEL.

CASAl, J. M. (2010a). Aproximación a las funciones de la jurisdicción constitucional, en Bogdandy, A. V., Ferrer MAC-Gregor, E. y MoRALES ANTONIAZZI, M. (coords.), La justicia constitucional y su internacionalización. ¿Hacia un Ius Constitutionale Commune en América Latina?, T. I. México, UNAM.

CASAL, J. M. (2010b). Los derechos fundamentales y sus restricciones, Caracas: Legis.

CASAL, J. M. (2011). "La relativización de la garantía de los derechos fundamentales por la Sala Constitucional del Tribunal Supremo de Justicia de Venezuela", en BAZÁN, V. y NASH, C., Justicia constitucional y derechos fundamentales. Fuerza normativa de la Constitución, Montevideo, Konrad Adenauer Stiftung.

CASAL, J. M. (2017a). Justicia y política: el caso de la jurisdicción constitucional en Venezuela, Konrad Adenauer Stiftung, disponible en: http:// www.kas.de/wf/doc/kas_48234-1522-4-30.pdf? 170316203548.

CASAl, J. M. (2017b). Asamblea Nacional: conquista democrática vs. demolición autoritaria. Elementos de la argumentación y práctica judicial autoritaria de la Sala Constitucional del Tribunal Supremo de Justicia. Caracas, UCAB.

CASAL, J. M. (2017c). Las transformaciones del constitucionalismo y la justicia constitucional, México, Porrúa.

CHAVERO, Rafael (2011). La justicia revolucionaria. Una década de reestructuración (o involución) judicial en Venezuela, Caracas, Aequitas. 
Esta revista forma parte del acervo de la Biblioteca Jurídica Virtual del Instituto de Investigaciones Jurídicas de la UNAM

Colombo CAmpBell, J. (2002). "Funciones del derecho procesal constitucional", Ius et Praxis, v. 8, núm. 2.

Comisión Interamericana de Derechos Humanos (2017). Situación de Derechos Humanos en Venezuela, OEA/Ser.L/V/II. Doc. 209, 31 de diciembre de 2017, disponible en: http://www.oas.org/es/cidh/informes/ pdfs/Venezuela2018-es.pdf.

CORZO, E. (2013). "El futuro de la justicia constitucional, con referencia a México”, en GonZÁLEZ PÉREZ, L. y VALADÉS, D., El constitucionalismo contemporáneo. Homenaje a Jorge Carpizo, México, UNAM.

Delgado, F. (2008). La idea de derecho en la Constitución de 1999, Caracas, Universidad Central de Venezuela.

FERnÁNDEZ SEgAdo, F. (1997). "Evolución histórica y modelos de control de constitucionalidad", en GARCía BELAÚNDE, D. y FERNÁNDEZ SEgAdo, F. (coord.), La jurisdicción constitucional en Iberoamérica, Madrid, Dykinson.

Ferreres Comella, V. (2009). Constitutional Courts and Democratic Values. A European Perspective, New Haven, Yale University Press.

FiX-ZAmudio, H. y Astudillo, C. (coord.) (2013). Estatuto Jurídico del juez constitucional en América Latina y Europa. Libro homenaje al doctor Jorge Carpizo, México, UNAM.

García Belaúnde, D. y Eguiguren Praeli, F., (2008). "La evolución político-constitucional del Perú 1976-2005”, Estudios Constitucionales, v. 6, núm. 2.

GARZÓN VALDÉS, E. (2003). "El papel del Poder Judicial en la transición a la democracia", Isonomía. Revista de Teoría y Filosofía del Derecho, núm. 18.

GONZÁLEZ-JÁCOME, J. (2019). "Authoritarianism and the narrative power of constitutionalism in Venezuela", en ALVIAR GARCíA, H. y FrANKENBERG, G., Authoritarian Constitutionalism, Cheltenham/Northampton, Edward Elgar.

HÄBERLE, P. (2004). "Die Menschenwürde als Grundlage der staatlichen Gemeinschaft", en IsEnSEe, J., KirchHOF, P., Handbuch des Staatsrechts der Bundesrepublik Deutschland, T. II, Heidelberg, Müller.

HARo, J. V. (2000), "La interpretación de la Constitución y la sentencia 1077 de la Sala Constitucional". Revista de Derecho Constitucional, núm. 2. 
Esta revista forma parte del acervo de la Biblioteca Jurídica Virtual del Instituto de Investigaciones Jurídicas de la UNAM

HERNÁNDEZ, J. I. (2016). "El asedio a la Asamblea Nacional", en BREWER-CARÍAS, Dictadura judicial y perversión del Estado de derecho, Caracas, Jurídica Venezolana.

HerRera Orellana, L. A. (2008). "El «recurso de interpretación» de la Constitución: reflexiones críticas desde la argumentación jurídica y la teoría del discurso", Revista de Derecho Público, núm. 113.

LANDA, C. (2010). Los precedentes constitucionales: el caso del Perú. Anuario Iberoamericano de Justicia Constitucional, núm. 14.

LANDAU, D. (2013). "Abusive Constitutionalism", U.C. Davis Law Review, online, vol. 47, núm. 1, disponible en: https://lawreview.law.ucda vis.edu/issues/47/1/articles/47-1_Landau.pdf(consulta: 19.08.2019).

LOUZA, L. (2017). "La estrecha y necesaria relación entre independencia judicial, Estado de derecho, el respeto de los derechos humanos y democracia. Venezuela como caso de estudio", Acta Sociológica [online], vol. 72. disponible en: http://www.revistas.unam.mx/index.php/ras/issue/view/4556/showToc.

Molina Galicia, R. (2002). Reflexiones sobre una nueva visión constitucional del proceso, y su tendencia jurisprudencial. ¿Hacia un gobierno judicial?, Caracas, Ediciones Paredes.

MöLlERS, C. (2011). "Legalität, Legitimität und Legitimation des Bundesverfassungsgerichts", en JESTAEDT, M. y otros, Das entgrenzte Gericht, Berlín, Suhrkamp.

Nogueira AlCALÁ, H. (2004). La jurisdicción constitucional y los tribunales constitucionales de Sudamérica en la alborada del siglo XXI, México, Porrúa.

Oficina del Alto Comisionado de las Naciones Unidas para los Derechos Humanos (2019). Informe de la Alta Comisionada de las Naciones Unidas para los Derechos Humanos sobre la situación de los derechos humanos en la República Bolivariana de Venezuela, A/HRC/41/18, 4 de julio de 2019, disponible en: https://www.ohchr.org/sp/newsevents/ pages/DisplayNews.aspx?NewsID $=24788 \&$ LangID $=S$ (consultado el 20.08.2019).

PARedes PAREDES, F. (2015). "La tutela jurisdiccional de los derechos fundamentales: una propuesta en clave democrática", Revista Chilena de Derecho, online, vol. 42, núm. 1, disponible en: https://dx.doi. org/10.4067/S0718-00122002000200002. 
Esta revista forma parte del acervo de la Biblioteca Jurídica Virtual del Instituto de Investigaciones Jurídicas de la UNAM

Petit Guerra, L. A. (2017). "La (in)justicia (in)constitucional: el caso Venezuela /A (in)justiça (in)constitucional: o caso Venezuela", Revista Brasileira de Direito, online, vol. 13, núm. 3, disponible en https://seer. imed.edu.br/index.php/revistadedireito/article/view/2204.

RUBIO LlORENTE, F. (2012). La forma del poder. Estudios sobre la Constitución, Madrid, Centro de Estudios Políticos y Constitucionales.

SÁNCHEZ FAlCón, E. (2017). Estado comunal y Estado federal en Venezuela: ¿son constitucionalmente conciliables ambas formas de Estado?, Caracas, Fundación Manuel García-Pelayo.

TAJADURA, J. (2006). "Retos y desafíos del derecho procesal constitucional en los umbrales del tercer milenio. Reflexiones desde la perspectiva europea", en FERRER MAC-GREGOR, E. (coord.), Derecho procesal constitucional, t. I. México, Porrúa.

TAYLOR, M. (2014). "The Limits of Judicial Independence: A Model with Illustration from Venezuela under Chávez", Journal of Latin American Studies.

VILLEGAS Salazar, M. (2000). "Comentarios sobre el recurso de interpretación constitucional en la jurisprudencia de la Sala Constitucional”, Revista de Derecho Público, núm. 84. 